\title{
Caffeine clearance by enzyme multiplied immunoassay technique: a simple, inexpensive, and useful indicator of liver function
}

\author{
J E McDonagh, V V Nathan, I C Bonavia, G R Moyle, A R Tanner
}

\begin{abstract}
The clinical value and sensitivity of serum caffeine clearance measurement has been evaluated as an indicator of hepatic disease. After a 17 hour caffeine exclusion period, $300 \mathrm{mg}$ of caffeine citrate was administered orally to the study subjects. Serum samples were taken four and 16 hours later. Serum caffeine concentrations were measured using an enzyme multiplied immunoassay technique (EMIT) and a clearance value derived. Conventional liver function tests were measured at the same time. A total of 103 subjects attending the medical unit in a district general hospital were studied. Twenty one had alcoholic liver disease, 11 non-alcoholic cirrhosis, nine noncirrhotic liver disease, 21 suspected liver disease, six hepatic tumours, and 35 were hospital and normal control subjects. Caffeine clearance values were lowest in subjects with alcoholic liver disease (median $0.19 \mathrm{ml} / \mathrm{min} / \mathrm{kg}$, range $0.04-0.61 \mathrm{ml} / \mathrm{min} / \mathrm{kg}$ ) and significantly reduced in all subjects with liver disease (median $0.32 \mathrm{ml} / \mathrm{min} / \mathrm{kg}$, range 0.04
\end{abstract} $2.68 \mathrm{ml} / \mathrm{min} / \mathrm{kg}$ ) compared with control subjects (median $1.27 \mathrm{ml} / \mathrm{min} / \mathrm{kg}, \mathbf{p}<0.001$ ). In subjects with suspected liver disease subsequently shown to have another explanation for abnormal liver function test results, caffeine clearance values were normal (median $1.31 \mathrm{ml}$ $\mathrm{min} / \mathrm{kg}$, range $0.23-2.64 \mathrm{ml} / \mathrm{min} / \mathrm{kg}$ ) and significantly different, $p<0.001$, from those of subjects with liver disease. Serum albumen values were not different for these latter two groups. Using a cut off value of $0.86 \mathrm{ml} / \mathrm{min} / \mathrm{kg}$, caffeine clearance measurement was $100 \%$ sensitive for alcoholic liver disease and $89 \%$ sensitive for all liver disease. The respective sensitivities for conventional liver function test measurement were $76 \%$ and $83 \%$. In the suspected liver disease group, caffeine clearance was abnormal in only $24 \%$, conventional liver function tests were abnormal in $95 \%$. The respective specificities for caffeine clearance and liver function test measurement in control subjects were $93 \%$ and $100 \%$. Caffeine clearance determined by EMIT is a simple inexpensive hepatic metabolic function test. This study indicates that it is a more sensitive indicator of structural liver disease than conventional liver function tests, especially for alcoholic liver disease. The test could be widely introduced as a useful, repeatable assessment of hepatic function.

Conventional liver function tests, especially of the various serum enzymes, provide important information on inflammation and cholestasis but give no indication of hepatic metabolic function. The major hepatic functions involve uptake of compounds from the bloodstream, metabolism of compounds within the liver, excretion of metabolites, and protein synthesis. The latter function can partly be judged by serum albumen and prothrombin time measurement. Caffeine $(1,3,7$ trimethylaxanthine) is primarily biotransformed $(97 \%)$ in the liver by microsomal drug metabolising enzymes and excreted in urine as methylxanthines. It seems to be an almost ideal substance for the assessment of hepatic metabolic function. It is safe, inexpensive, almost completely absorbed, metabolised exclusively by the liver, and is simply assayed in blood or saliva using an enzyme multiplied immunoassay technique (EMIT). ${ }^{1}$ The main reservations concerning this compound relate to a decline in caffeine elimination with advancing age, induction of metabolism by cigarette smoking, ${ }^{2}$ and impairment of elimination by certain drugs such as cimetidine. ${ }^{3}$

With the development of hepatic transplantation, the need for a simple informative liver function test that provides possible prognostic information, such as creatinine clearance in renal disease, has become important. Quantitative tests such as the aminopyrine breath test, galactose elimination, and indocyanine green clearance have been developed but are not widely available either because of technical difficulties or adverse effects. With the advent of the caffeine EMIT assay, caffeine clearance measurement could be widely introduced, and we therefore detail our results in 103 subjects presenting to a district general hospital.

Patients and methods

Sixty eight consecutive patients with actual or suspected liver disease admitted to the medical wards at North Tees General Hospital were studied. All subjects were suspected of having liver disease on initial presentation and subsequent investigations either confirmed or refuted this. At the same time 14 normal control subjects and 21 subjects admitted with other medical conditions were studied; the latter were matched for age and sex with liver disease subjects. The following diagnostic groups were established after full investigation, including liver biopsy where appropriate.

Group I comprised 21 patients with alcoholic liver disease. Their mean age was 52.7 years (range 19-71 years). Nineteen of these subjects had histological confirmation, two had a severe coagulopathy precluding biopsy. Seventeen had 
TABLE I Subjects in whom liver disease was initially suspected but who were subsequently shown to have an alternative diagnosis (group IV)

\begin{tabular}{rll}
\hline $\begin{array}{l}\text { Patient } \\
\text { no }\end{array}$ & Final diagnosis & $\begin{array}{l}\text { Caffeine } \\
\text { clearance } \\
(\mathrm{ml} / \mathrm{min} / \mathrm{kg}) \\
(\text { normal }>0 \cdot 86)\end{array}$ \\
\hline 1 & Ampullary carcinoma & $0 \cdot 45$ \\
2 & Septicaemia & $0 \cdot 91$ \\
3 & Septicaemia & $0 \cdot 46$ \\
4 & Septicaemia & $2 \cdot 64$ \\
5 & Panniculitis & $1 \cdot 16$ \\
6 & Rheumatoid arthritis & $1 \cdot 38$ \\
7 & Lobar pneumonia & $2 \cdot 10$ \\
8 & Non-Hodgkins lymphoma & $1 \cdot 83$ \\
9 & Hepatomegaly, normal biopsy & $1 \cdot 02$ \\
10 & Carcinoma pancreas & $0 \cdot 76$ \\
11 & Rheumatoid arthritis, chronic & $0 \cdot 23$ \\
12 & lymphatic leukaemia & $1 \cdot 23$ \\
13 & Hepatomegaly, normal biopsy & $1 \cdot 17$ \\
& Diabetes, chronic obstructive & \\
14 & pulmonary disease & $0 \cdot 32$ \\
15 & Scleroderma & $1 \cdot 31$ \\
16 & Guillain-Barré & $1 \cdot 56$ \\
17 & Cystic fibrosis & 1.95 \\
18 & Common bile duct stone & $1 \cdot 38$ \\
19 & Common bile duct stone & $2 \cdot 35$ \\
20 & Common bile duct stone & $2 \cdot 21$ \\
21 & Common bile duct stone & $1 \cdot 52$ \\
\hline
\end{tabular}

confirmed cirrhosis and two alcoholic hepatitis with central hyaline sclerosis.

Group II comprised 11 patients with hepatic cirrhosis not related to alcohol. Their mean age was $64 \cdot 3$ years (range $52-82$ years). All subjects had histological confirmation of disease. Five had autoimmune liver disease, four cryptogenic cirrhosis, and two haemochromatosis.

Group III comprised nine patients with noncirrhotic liver disease. Their mean age was 36.8 years (range 16-66 years). There were five patients with acute hepatitis, two with portal vein thrombosis (but increased hepatic fibrosis on biopsy specimen), and one each with granulomatous hepatitis and unexplained severe fatty liver.

Group IV comprised 21 patients with suspected liver disease. Their mean age was 61.8 years (range $20-85$ years). This group included patients who were initially suspected of having liver disease because of abnormal liver function tests or hepatomegaly but who were subsequently shown to have an alternative explanation for these abnormalities, see Table I.

TABLE II Hospital control subjects (group VI)

\begin{tabular}{|c|c|c|}
\hline $\begin{array}{l}\text { Patient } \\
\text { no }\end{array}$ & Diagnosis & $\begin{array}{l}\text { Caffeine } \\
\text { clearance } \\
(\mathrm{ml} / \mathrm{min} / \mathrm{kg}) \\
(\text { normal }>0 \cdot 86)\end{array}$ \\
\hline 1 & Diabetes mellitus & $1 \cdot 71$ \\
\hline 2 & Myocardial infarct & $1 \cdot 83$ \\
\hline 3 & Chronic obstructive pulmonary disease & $1 \cdot 11$ \\
\hline 4 & Angina & $1 \cdot 64$ \\
\hline 5 & Chronic obstructive pulmonary disease & 1.62 \\
\hline 6 & Chronic obstructive pulmonary disease & $1 \cdot 19$ \\
\hline 7 & Atypical chest pain & 0.98 \\
\hline 8 & Chronic obstructive pulmonary disease & 1.00 \\
\hline 9 & Pulmonary embolus & $0 \cdot 82$ \\
\hline 10 & Asthma & $0 \cdot 83$ \\
\hline 11 & Angina, Rheumatoid disease & $1 \cdot 33$ \\
\hline 12 & Myocardial infarct & 0.64 \\
\hline 13 & Myocardial infarct & $2 \cdot 51$ \\
\hline 14 & Myocardial infarct & $2 \cdot 09$ \\
\hline 15 & Asthma & 0.63 \\
\hline 16 & Asthma & 0.66 \\
\hline 17 & Atypical chest pain & 0.56 \\
\hline 18 & Angina & 0.73 \\
\hline 19 & Chronic obstructive pulmonary disease & $1 \cdot 38$ \\
\hline 20 & $\begin{array}{l}\text { Chronic obstructive pulmonary disease, } \\
\text { rheumatoid disease }\end{array}$ & $0 \cdot 10$ \\
\hline 21 & Chronic pancreatitis & $2 \cdot 01$ \\
\hline
\end{tabular}

Group V comprised six patients with hepatic tumours. Their mean age was 72 years (range 38-90 years). There was one hepatoma in a subject with haemochromatosis, one cholangiocarcinoma, and four subjects with advanced metastatic adenocarcinomata.

Group VI comprised 21 hospital control subjects. Their mean age was 56.9 years (range 23-82 years). This group consisted of inpatients on the medical unit who were known not to have liver disease (suspected or proved), see Table II.

Group VII comprised 14 normal control subjects. Their mean age was 33.5 years (range 24-48 years). This group consisted of healthy hospital staff.

Informed consent was obtained from all subjects and the study received approval from the district ethical committee in May 1989.

\section{EXPERIMENTAL PROCEDURE}

The subjects complied with a caffeine free diet from midnight before the test. At $5 \mathrm{pm}$ on the day of the test, $300 \mathrm{mg}$ of caffeine citrate was administered orally to each subject in two cups of decaffeinated coffee. Venous blood was taken at 9 pm and at 9 am the following morning when the caffeine restriction was lifted. Blood for conventional liver function tests was taken with the morning sample.

\section{ANALYTICAL METHODS}

Routine liver function tests were undertaken using standard methods in the hospital laboratory. Serum samples were stored at $-20^{\circ} \mathrm{C}$ and

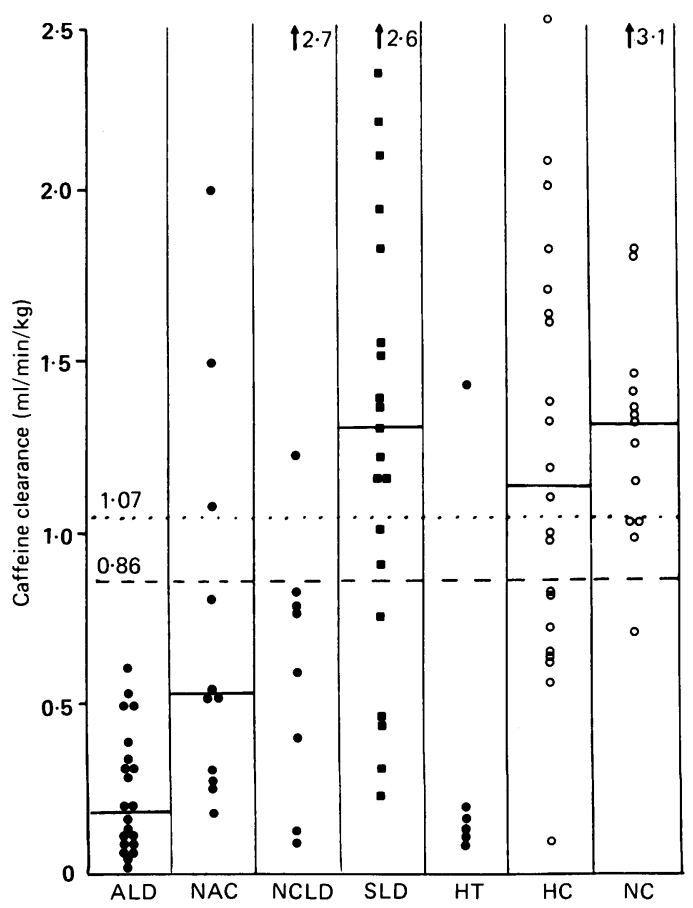

Individual caffeine clearance values. Arrows indicate values off scale. The interrupted line is the lower limit of normal derived from normal control values and the dotted line, the lower limit of normal as defined in reference ${ }^{1}$. The median value for each group is indicated by a line in each column. $A L D=$ alcoholic liver disease; $N A C=$ non-alcoholic cirrhosis, $N C L D=$ non-cirrhotic liver disease; $S L D=$ suspected liver disease; $H T=$ hepatic tumours; $H C=$ hospital controls; $N C=$ normal controls. 
assayed in batches. Caffeine serum concentrations were determined by the method described by Zysset et al, ${ }^{4}$ using an automated enzyme immunoassay kit supplied by Syva, UK. Caffeine content remained stable for at least three months under these storage conditions. In five subjects (three controls and two with stable liver disease) reproducibility was assessed by repeating the test after a month. The coefficient of variation was $13 \cdot 7 \%$.

The caffeine elimination constant $\left(k_{e l}\right)$ was calculated assuming first order kinetics. A recent study ${ }^{5}$ has confirmed the validity of estimating caffeine clearance using only two data points. Previous studies in man have shown that caffeine elimination follows first order kinetics after this oral dose, which is maintained beyond several half lives. ${ }^{6}$ Caffeine clearance was calculated as $\mathrm{Cl}=\mathrm{k}_{\mathrm{el}} \times \mathrm{V}_{\mathrm{d}}$, using a constant volume of distribution of $0.61 / \mathrm{kg}$ body weight. Other studies have shown that caffeine distributes in total body water and that $V_{d}$ for caffeine is not significantly different in cirrhotic patients.

\section{STATISTICS}

All comparisons between groups have been made using the Mann-Whitney $U$ test. Sensitivity is defined as the number of true positives in a population as a proportion of true positives plus false negatives; specificity is defined as the number of true negatives in a population as a proportion of true negatives plus false positives.

\section{Results}

The individual results for measurement of caffeine clearance are shown in Figure 1 and the median values for each group are shown in Table III with serum albumen results for comparison. Caffeine clearance is most depressed in the patients with alcoholic liver disease and significantly different $(p=0.003)$ even when compared with non-alcoholic cirrhosis. There is no significant difference in the albumen measurement for these two groups. In the suspected liver disease group, caffeine clearance values were not different from normal values but were significantly higher than values for subjects with proved liver disease $(\mathrm{p}<0.001)$ despite noticeable abnormalities in liver enzyme and bilirubin measurements. This is best shown for the subjects with jaundice associated with obstructing common duct stones whose caffeine clearance values were all normal (see Table I). Their respective peak bilirubin values were $163,251,39,20$, and $53 \mu \mathrm{mol} / \mathrm{l}$.

Subjects with hepatic tumours tended to have noticeably depressed caffeine clearance values (see Fig 1) but all had advanced disease requiring admission for terminal care planning. The one subject with a normal value had a metastatic adenocarcinoma affecting the liver.

A value of $0.86 \mathrm{ml} / \mathrm{min} / \mathrm{kg}$ has been used as a cut off value (mean of normal control values minus 1SD), ' for assessing sensitivity and specificity. In the alcoholic liver disease group caffeine clearance measurement was $100 \%$ sensitive compared with a $76 \%$ sensitivity for conventional liver function tests. Conventional liver
TABLE III Median caffeine clearance and serum albumen measurements for the various groups. (Values, median (range).)

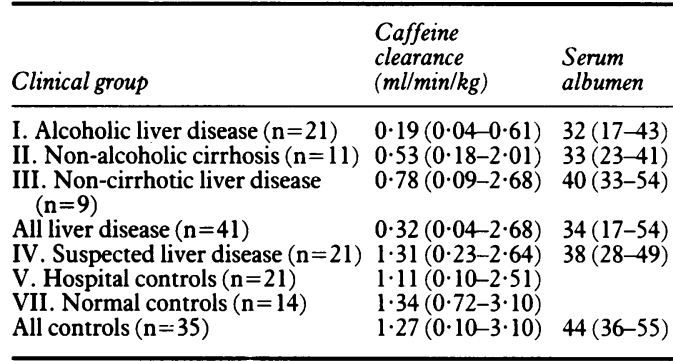

Statistical comparisons for caffeine clearance.

All liver disease $v$ all controls $\mathrm{p}<0 \cdot 001$.

All liver disease $v$ suspected liver disease,

All liver disease $v$ suspected liver disease, $\mathrm{p}<0.001$

Statistical comparison for serum albumen.

All liver disease $v$ suspected liver disease, $\mathrm{p}=0 \cdot 07$

function tests were regarded as indicating disease if any one of alkaline phosphatase, aspartate transaminase, bilirubin, or albumen values were abnormal. For all patients with proved liver disease caffeine clearance measurement was $89 \%$ sensitive compared with $83 \%$ for conventional liver function tests. In non-alcohol related cirrhosis, $91 \%$ showed abnormal liver function tests but only $72 \%$ had an abnormal caffeine clearance value probably indicating a stable compensated cirrhosis in a number of these subjects.

In the suspected liver disease group, the caffeine clearance measurement was abnormal in only $24 \%$ of subjects compared with abnormal liver function tests in $95 \%$, the latter reflecting the underlying disease rather than structural liver disease. Specificity for liver function tests and caffeine clearance measurement was $100 \%$ and $93 \%$ respectively in normal control subjects. In the hospital control group the specificity of caffeine clearance measurement was poor $(62 \%)$.

\section{Discussion}

Since the initial observation that the half life of caffeine is prolonged in patients with alcoholic liver disease, ${ }^{7}$ several studies have shown that caffeine clearance measurement is a reliable indicator of the severity of liver disease. ${ }^{1+58}$ After the introduction of an EMIT kit for the assay of caffeine, the measurement of caffeine in biological fluids is now an inexpensive and simple procedure that any laboratory can establish. The potential value of this measurement has been assessed in a district hospital setting.

An arbitrary lower limit of normal for caffeine clearance measurement has been set at $0.86 \mathrm{ml} /$ $\mathrm{min} / \mathrm{kg}$. This has been derived from a rather small control population but is similar to the value of $1.07 \mathrm{ml} / \mathrm{min} / \mathrm{kg}$ derived by Jost et al (and shown for comparison in the Figure). A more useful cut off value might be derived by receiver operating curve (ROC) analysis. Nevertheless, the derived values for specificity and sensitivity give some impression of test performance. Caffeine clearance measurement alone is at least as useful as conventional liver function tests in detecting liver disease but we feel that its measurement, in addition to conventional liver function test measurement, gives a more comprehensive indication of the severity of 
the liver disease. This is certainly indicated in our data relating to cirrhosis, where $91 \%$ of those with this disorder have an abnormal caffeine clearance value, whose median of $0.38 \mathrm{ml} / \mathrm{min} /$ $\mathrm{kg}$ is significantly lower than that of patients with non-cirrhotic liver disease $(0.78 \mathrm{ml} / \mathrm{min} / \mathrm{kg}$ $\mathrm{p}=0 \cdot 04)$. A number of transplant centres use caffeine clearance measurement as a useful prognostic indicator and there is evidence that it is a more sensitive indicator of declining hepatic function than the aminopyrine breath test. ${ }^{9}$ After orthotopic liver transplantation, caffeine clearance measurement is a poor means of predicting impending transplant rejection. ${ }^{10}$ This is not surprising in a structurally normal organ where the predominant injury, except in severe cases, is periportal. Changes probably occur too rapidly in this situation for any function test to perform more reliably than simple enzyme estimation and histology. A recent study has shown that the inclusion of a test of hepatic metabolic function in the assessment of the prognosis of liver disease greatly simplifies the process, reducing the number of variables required."

Caffeine clearance values were low in a number of hospital control subjects. This may have reflected the severity of their underlying disease or incomplete information concerning possible liver disease. Potential drug interference with the assay and inhibition of caffeine metabolism were avoided as far as possible, although changing complex drug therapy may have had an influence. Many studies have shown the wide variation in caffeine clearance values between individuals, often influenced by environmental factors such as smoking. This contributes to the difficulty in establishing a clear threshold value for 'normal'. Information on smoking habits was obtained from all subjects but separate analysis by smoking habit did not improve discrimination between or within the various groups. In fact only 27 subjects were current smokers. The highest observed clearance value (3.1 in a normal control) was in the heaviest smoker! In the patients with cirrhosis not related to alcohol, three had normal caffeine clearance values; one with chronic active hepatitis, one with sclerosing cholangitis, and one with haemachromatosis. The last subject was the only smoker. Of the subjects with normal caffeine clearance values who had liver disease $(n=6)$, only two were current smokers while four of the 20 subjects with low values were also smokers. Twelve of the 21 patients with alcoholic liver disease were current smokers but their caffeine clearance values (median $0.23 \mathrm{ml} / \mathrm{min} / \mathrm{kg}$ ) were lower than those of non-smokers in the same group (median $0.37 \mathrm{ml} / \mathrm{min} / \mathrm{kg}$ ). Thus, in this study smoking habit did not have any consistent influence on the interpretation of the results.

In the present study it is striking that those with alcoholic liver disease have the most homogeneous and depressed values. This probably reflects the fact that those patients with alcoholic liver disease were often admitted to hospital for liver biopsy with decompensated disease or alcoholic hepatitis. Less severe forms of alcoholic liver disease were unlikely to be admitted or to undergo biopsy. A further factor in the uniform depression of caffeine clearance values in alcoholic liver disease may be the pattern of injury to the liver acinus by alcohol. Damage is predominantly centrilobular, the area of highest concentration of microsomal drug metabolising enzymes. Damage in this area may result in a more profound depression of caffeine clearance than processes resulting in a more diffuse or periportal pattern of injury. It is interesting to note that patients with severely abnormal liver function tests as a result of duct obstruction had quite normal caffeine clearance values (apart from the patient with ampullary carcinoma).

Previous studies ${ }^{1}$ have documented the higher sensitivity for detecting liver disease of formal hepatic function tests such as caffeine clearance, aminopyrine breath test, or galactose elimination capacity (70-80\% sensitive) compared with conventional liver function tests such as prothrombin time, bilirubin, or albumen $(10-30 \%$ sensitive). With the advent of the EMIT assay, caffeine clearance measurement should no longer be restricted to research institutions but could now become part of the standard evaluation of hepatic function in any hospital. The findings of the present study indicate that this test is as sensitive as conventional liver function tests, is easy to develop in any hospital, is harmless, inexpensive, easily repeated, and provides potentially valuable prognostic information.

1 Jost G, Wahllander A, Mandach U, Preisig R. Overnight salivary caffeine clearance: a liver function test suitable fo routine use. Hepatology 1987; 7: 338-44.

2 Joeves R, Klinker H, Heuster H, Epping J, Zilly W, Richter $\mathrm{E}$. Influence of smoking on caffeine elimination in healthy volunteers and in patients with alcoholic liver disease. Hepatology 1988; 8: 575-9.

3 Broughton LJ, Rogers HJ. Decreased systemic clearance of caffeine due to cimetidine. Br $\mathcal{F}$ Clin Pharmac 1981; 12 $155-9$.

4 Zysset T, Wahllander A, Preisig R. Evaluation of caffeine plasma levels by an automated enzyme immunoassay (EMIT) in comparison with a high-performance liquid chromatograpic method. Ther Drug Monitoring 1984; 6: chromatogr

5 Wahllander A, Mohr S, Paumgartner G. Assessment of hepatic function. Comparison of caffeine clearance in serum and saliva during the day and at night. $\mathcal{F}$ Hepatol 1990; 10: 129-37.

6 Bonati M, Latini R, Galletti F, Young JF, Tognoni G, Garattini S. Caffeine disposition after oral doses. Clin Pharmacol Ther 1982; 32: 98-106.

7 Desmond PV, Patwardhan RV, Johnson RF, Schenker S Impaired elimination of caffeine in cirrhosis. Dig Dis Sci 1980; 25: 193-7.

8 Renner E, Weitholtz H, Huguenin P, Arnaud MJ, Preisig R. Caffeine: a model compound for measuring liver function. Hepatology 1984; 4: 38-46.

9 Chepatology 1984; 4: 38-46. Halliday JW, Powell LW. Serial caffeine and antipyrine clearances in the assessment of disease progression with particular reference to liver transplantation. Hepatology 1988; 8: 1403A.

10 Nagel RA, Dirix LY, Hayllar KM, Preisig R, Tredger JM, Williams $R$. Use of quantitative liver function tests - caffeine clearance and galactose elimination capacity - after orthotopic liver transplantation. F Hepatol 1990; 10: 149-57.

11 Adler M, van Laethem J, Glibert A, Gelin M, Bourgeois N, Vereerstraeten $P$, Cremer $M$. Factors influencing survival at one year in patients with non-biliary hepatic parenchyma cirrhosis. Dig Dis Sci 1990; 35: 1-5. 